\title{
Determining the optimal operating parameters of a wind system
}

\author{
Cornel Cătălin Gavrilă ${ }^{1}$ and Radu Săulescu ${ }^{2}$ \\ ${ }^{1}$ Transilvania University of Brasov, Romania \\ 2 Transilvania University of Brasov, Romania
}

\begin{abstract}
The paper main objective is to determine the representative parameters for the geometrical modeling of the speed amplifiers used in the high-capacity wind systems, taking into account the assembling and also the neighboring conditions of the satellite wheels in the planetary units. The analysis is based on a case study taken from a representative producer in this field - a speed amplifier for which is known: wind rotor diameter, type of speed amplifier and electric generator. Starting from these data and from the power curve offered by each wind device producer, the paper presents the synthesis of the number of teeth and the efficiency of such an amplifier taking into account the electrical and wind parameters (wind velocity, density air, wind rotor diameter). Based on the electrical and wind parameters, the system's power factor is determined to determine the efficiency of the speed amplifier and the wind speed at which the system can work best.
\end{abstract}

\section{Introduction}

The main function of a speed multiplier is to transmit, with constant ratio, the mechanical power, converted from the wind, to the electric generator, for the production of electric power. This involves identifying a system that works best to achieve the functional correlation between the wind turbine and the electric generator.

Usually, the rotor blades rotate effectively at low speeds to maintain its peak velocity in the subsonic wavelength range. For example, large rotors are rotating at $20 \ldots 30 \mathrm{rpm}$, while generators have a nominal speed of 1500 or $3000 \mathrm{rpm}$; therefore, the amplification ratio of a speed amplifier is in the range 50 to 150 [1].

Most large-capacity wind turbine systems uses highspeed, single-input and output-output multipliers: a planetary unit and two outer cylindrical gears [2], two planetary units and a cylindrical outer gear [3] or three planetary units [4].

A similar variant to that proposed by Suzuki [3] is that proposed by Leimann [5]. The structural schemes of the both two solutions are shown in Fig.1, a, respectively $\mathrm{b}$, and represents the constructive solution studied in the present paper.

\section{The Speed Amplifier}

In practice, most wind power manufacturer companies presents to potential customer some technical data, as rotor diameter $\left(D_{R}\right)$ and wind speed rotor $\left(n_{R}\right)$; the constructive type and the speed of the multiplier transmission and its multiplier ratio; the electrical power obtained by the electric generator and its efficiency, as well as the power curve of the wind system, without saying how efficient the system is, at what wind speed it works best or what should be the number of wheel teeth in the multiplier transmission, to allow the client to obtain an optimal transmission ratio on each gear that corresponds to the multiplied speed value provided by the prospectus.

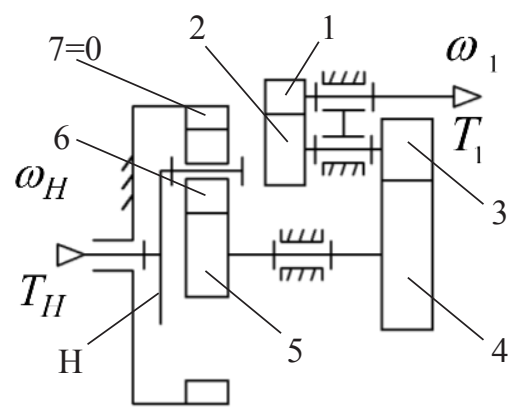

a. Structural scheme for Suzuki multiplier

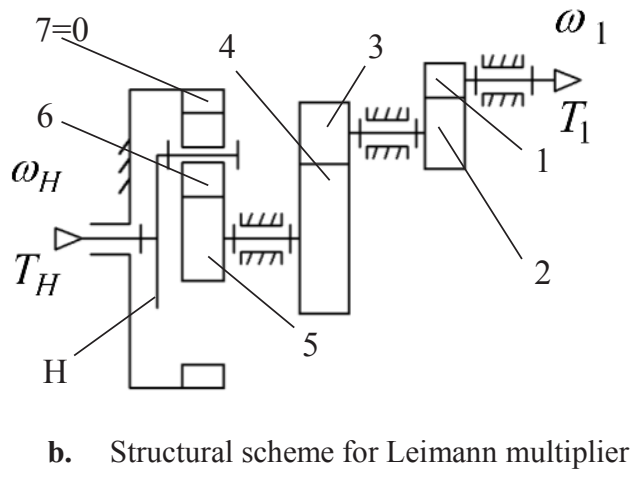

Fig.1. Structural schemes for speed multiplier [6]

According to the manufacturer recommendations [B] and structural schemes presented in Fig. 1, such systems consist in a planetary unit (composed by the satellite gear support carrier $\mathrm{H}$, the sun gear 5 , the satellite

\footnotetext{
* Corresponding author: rsaulescu@unitbv.ro
} 
6 and also by the fixed crown gear 7) and two steps multiplier gears ( 3 and 4 respectively 1 and 2), connected in series.

The winding rotor is rigidly connected to the satellite gear support carrier $\mathrm{H}$ of the speed amplifier planetary unit, whose multiplied speed output is transmitted to the next multiplier step with gears and finally to the rotor of the electric generator. So, the multiplier transmission inputs are the rotation $\left(\omega_{\mathrm{H}}\right)$ and torque $\left(\mathrm{T}_{\mathrm{H}}\right)$, given by wind rotor. The outputs are the rotation $\left(\omega_{1}\right)$ and torque $\left(\mathrm{T}_{1}\right)$, to be transmitted to the electric generator rotor.

Starting from the structural scheme of the amplifier, it is proposed to determine the transmission ratios of the two gears and the planetary unit teeth numbers, so that the transmission has the multiplier ratio given by the manufacturer [7]. Based on this, is proposed the algorithm for determining the geometrical parameters of a speed multiplier based on wind parameters, electrical, multiplying ratio and wind power curve, as well as at what wind speed the system considered can work optimally.

\section{Wind Power Efficiency}

The electrical power of a wind turbine that works at a constant speed depends on the input speed of rotation. Thus, for a low rotation speed, the power reaches the maximum value at a low wind speed. A wind system that operates at high speed extracts a large amount of energy at high wind speeds, while functioning inefficiently $[8,9]$.

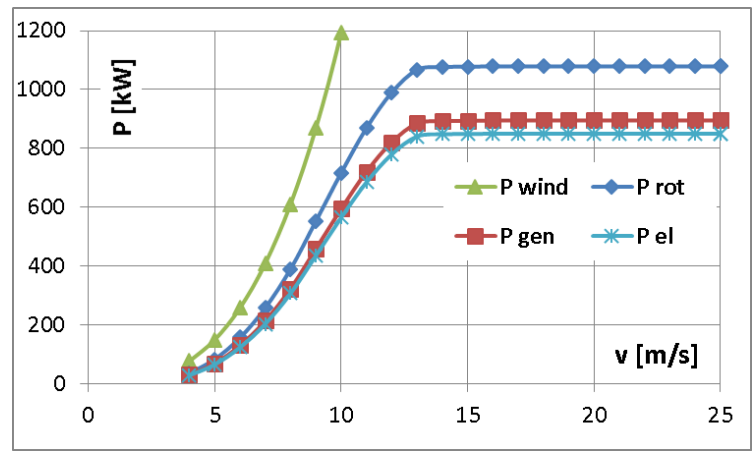

Fig.2. The power curves for the studied wind system

Starting from these, it is proposed to determine the power factor (the efficiency) of the system, based on the power curve, considered known (Fig. 2). The wind turbine power is given by relation

$$
P_{e l}=\frac{1}{2} \cdot \rho \cdot c_{p} \cdot A \cdot v^{3}=P_{\text {wind }} \cdot c_{p},
$$

where $\mathrm{P}_{\mathrm{el}}$ is the power of a wind turbine (for the studied case, the installed capacity, $\left.P_{\mathrm{el}}=850 \mathrm{~kW}\right), \rho$ is the air density, (the value $\rho=1.2255$ is considered at sea level at the temperature of $15^{\circ} \mathrm{C}$ ), $A$ is the swept area (the area covered by the studied rotor while rotating, $A=2124 \mathrm{~m}^{2}$ ) and also, $v$ is the wind speed. From the relation (1) results the power factor for the studied wind system

$$
c_{p}=\frac{P_{e l}}{P_{\text {wind }}}=\frac{P_{e l}}{\frac{1}{2} \cdot \rho \cdot A \cdot v^{3}} .
$$

Taking accounting that the power factor $\left(c_{\mathrm{p}}\right)$ of the wind system depends by the efficiency of the winding rotor $\left(\eta_{\text {rot }}\right)$, the speed multiplier efficiency $\left(\eta_{\mathrm{a}}\right)$ and also by the generator efficieny ( $\eta_{\text {gen }}=0.95$, value given by the manufacturer [7], adopting the theoretical yield of a fixed axle gear $\left(\eta_{\text {ang }}\right)$, the efficiency of wind turbine is determined, as it is presented in Fig. 3, a, b).

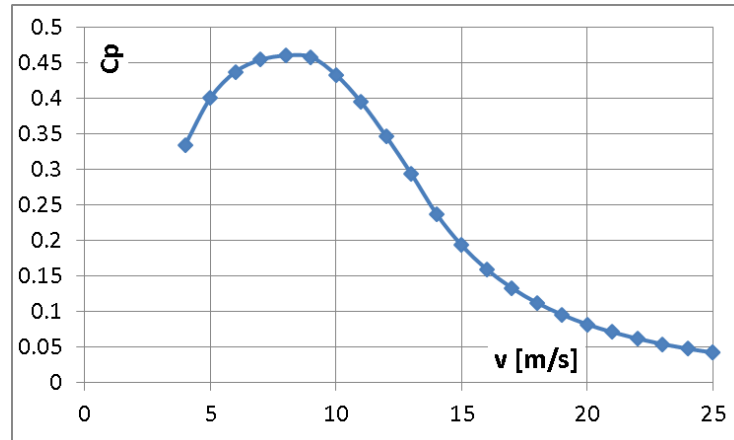

a. The efficiency depending by the wind speed

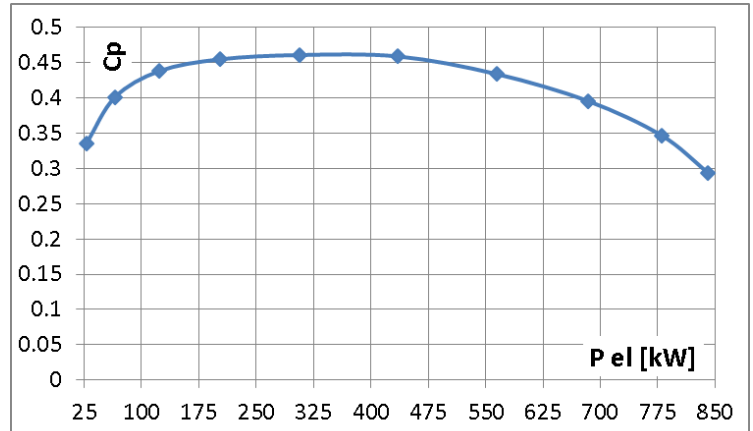

b. The efficiency depending by the electric power

Fig.3. The studied wind system efficiency

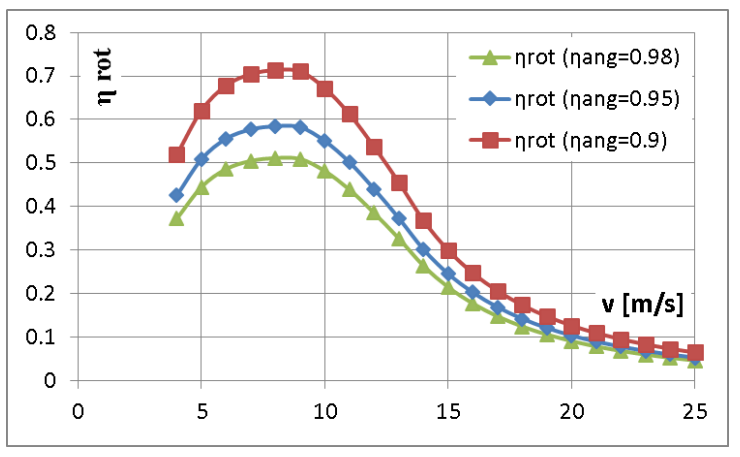

Fig. 4. The winding rotor efficiency, depending by various fixed axle gear efficiency values

The winding rotor efficiency is given by relation

$$
\eta_{\text {rot }}=\frac{c_{p}}{\eta_{\text {ang }} \cdot \eta_{g e n}}
$$


and can be determined, depending by the gear efficiency, as is presented in Fig. 4.

Once determined, it is compared with the theoretical values and then it is possible to perform the synthesis of the planetary speed multiplier for given efficiency for fixed axle gear.

Since the literature [1] recommends wind turbine efficiency $40 \ldots 60 \%$, the value adopted for the efficiency of a fixed axle gear will be $95 \%$, for which the average wind rotor yield is approx. $45 \%$. The previous values are useful in the wind system power curves obtained for the wind power $\left(P_{\text {wind }}\right)$, the wind power turbine $\left(P_{\text {rot }}\right)$ and also for the mechanical power to the electric generator input $\left(P_{\text {gen }}\right)$ (see also Fig. 2).

\section{Statics and Kinematics}

The static and kinematic modeling presented below is based on the block diagram of the speed multiplier presented in Fig. 6.

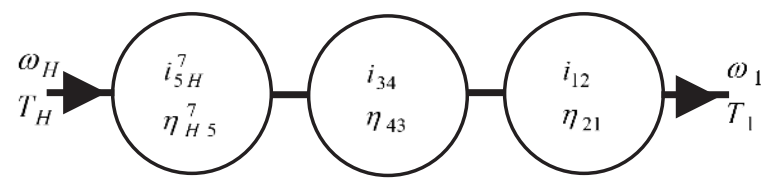

Fig.6. The speed amplifier block diagram

In the presented block diagram, the transmission ratio are written for each gear step of the speed amplifier, from the output to input, and led to the multiplier ratio.

According to Fig. 1, for given values the values for the planetary unit multiplying ratio $\left(i_{\mathrm{a}}=61.74\right)$ and the efficiency for fixed axle gear $\left(\eta_{\text {ang }}=0.95\right)$, the main kinematic and static parameters are given by relations:

$$
\begin{gathered}
i_{a}=i_{1 H}=i_{5 H}^{7} \cdot i_{34} \cdot i_{12}, \\
\eta_{a}=\eta_{H 1}=\eta_{H 5}^{7} \cdot \eta_{43} \cdot \eta_{21} .
\end{gathered}
$$

To perform the synthesis of the planetary gear teeth numbers of the speed multiplier, the standardized gear ratio [10] for the fixed axle gears are adopted $\left(i_{12}=3.15\right.$ respectively $\left.i_{34}=3.55\right)$ and the transmission ratio of the planetary unit, $i_{5 H}^{7}$, is determined by

$$
i_{5 H}^{7}=\frac{i_{a}}{i_{34} \cdot i_{12}}=\frac{61.74}{(-3.55) \cdot(-3.15)}=5.52
$$

where:

$$
i_{5 H}^{7}=1-i_{57}^{H}=1-i_{0 I}=5.52
$$

By adopting the efficiency value for the, the efficiency values for the each multiplying fixed axle gear steps ( 3 and 4 respectively 1 and 2 ) as well as the internal efficiency for the planetary unit result as:

$$
\eta_{43}=\eta_{21}=\eta_{\text {ang }}=0.95 \text {, }
$$

$$
\eta_{0 I}=\eta_{57}^{H}=\eta_{56} \cdot \eta_{67}=0.95^{2}=0.9025
$$

To determine the yield of the speed multiplier efficiency, the planetrary unit efficiency is determined by relation:

$$
\eta_{H 5}^{7}=\frac{-\omega_{57} \cdot T_{5}}{\omega_{H 7} \cdot T_{H}}=-\frac{T_{5} / T_{H}}{i_{H 5}^{7}}=\frac{\left(1-i_{0 I}\right)}{1-i_{0 I} \cdot\left(\eta_{0 I}\right)^{x}},
$$

where $\mathrm{x}=\operatorname{sgn}\left(\omega_{5 \mathrm{H}} \cdot \mathrm{T}_{5}\right)=-1$.

Taking account by relations (5), and ( $7 \ldots 10)$ for the multiplier efficiency the following value is obtained:

$$
\eta_{a}=\frac{1+4.52}{1+4.52 / 0.9025} \cdot 0.95 \cdot 0.95=0.8291 .
$$

The previous results led to the multiplying functions for the analyzed speed amplifier:

$$
\begin{gathered}
\omega_{1}=i_{a} \cdot \omega_{H}=61.74 \cdot \omega_{H}, \\
T_{1}=-i_{a} \cdot \eta_{a} \cdot T_{H}=-51.19 \cdot T_{H} .
\end{gathered}
$$

So, the input rotation value is multiplied by 61.74 and the input torque value is reduced by 51.19 .

\section{Gears Teeth Numbers in Planetary Unit}

A problem with this type of multiplier could be the load through the planetary unit, related with the wind turbine load, which is the most demanding; therefore a stage of constructive design is that of its geometrickinematic synthesis. For this purpose, is considered the type of planetary unit presented in Fig. 1 and the internal kinematic ratio $i_{0 \mathrm{I}}$ given by relation (7); also there are constraints given by the outer dimensions of the planetary unit, which led to the teeth number adopting for the crown wheel $\left(\mathrm{z}_{7}\right)$. With this data, it is proposed to determine the number of tooth numbers of the component wheels and the number of satellites (s). Then, the geometrical sizes of the gears can be determined and the mechanical power transmission through the speed amplifier established.

For study, the planetary unit can be considered as fixed axle gear, obtained by the motion inversion. Inside, there are needed the following constructive conditions: satellite parallel mounting, axis coincidence between the sun and crown gear, neighborhood condition between the satellites. The number of satellites $(s)$ can be determined depending by their tooth numbers (where $N$ is an integer), for which the neighboring condition $[C]$ will be checked. The calculus example presented in Fig. 6 [10] led to a number of 4 satellites $(s=4)$. Based on the parameters from Fig. 6, the constructive scheme for the planetary unit is obtained (Fig. 7). 


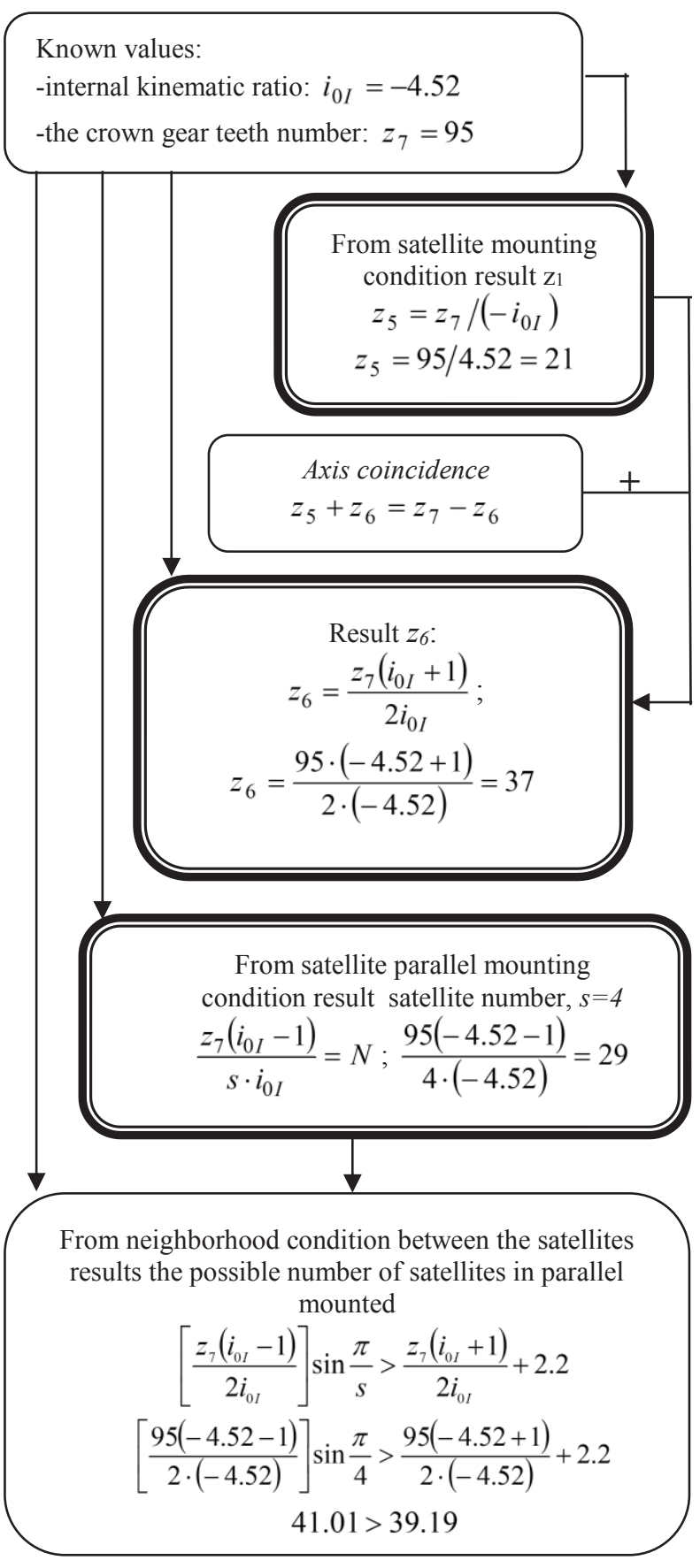

Fig.6. Teeth numbers synthesis algorithm

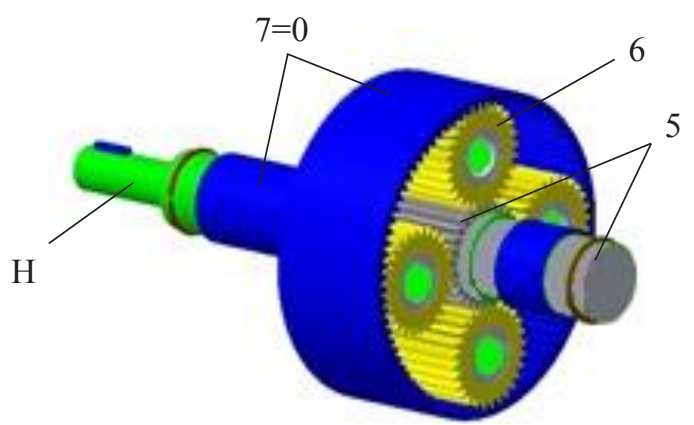

Fig.7. Planetary unit constructive variant

\section{Conclusions}

From the diagrams presented in Fig. 3, it can be observed that wind systems are more efficient before reaching the rated electrical power given by the generator.

Increasing wind speeds, and also the electricity production, increases the risks of optimal use of the wind system, so the additional loads on blades, wind speed amplifier respectively wind turbine. Taking into account the above, it can be said that the performance of a wind system depends mainly on the performance of the rotor, the speed amplifier and the electric generator.

The proposed synthesis algorithm led to the optimum number of wheel teeth inside the transmission to determine geometric parameters and loads transmitted by each gear, shaft and bearings; this being the subject of a future work. The analysis of the results highlights that the selection of certain combinations of transmission reports, which should be applied in a practical case, depends on the design requirements set, in a pre-feasibility study.

\section{References}

1. Hau E., Wind Turbines: Fundamentals, Technologies, Application, Economics, Springer, Germany, 2006.

2. Tong W., Wind Power Generation and Wind Turbine Design, WIT Press, 2010.

3. Suzuki K., a. o, Planetary gear train with oiling system for supplying lubricant oil to bearing, Patent no. US20130172144 A1, 2013.

4. Carriveau R., Fundamental and Advanced Topics in Wind Power, InTech, Rijeka, 2011.

5. Leimann D., Planetary gear unit for a gearbox for a wind turbine, Patent no. US20110077120 A1, 2011.

6. Vișa, I., a. o, The Role of Mechanisms in Sustai-nable Energy Systems. Ed. Universităţii Transilvania din Braşov, 2015 (in romanian).

7. Gamesa Catalogue, Wind Turbine G52-850kW, 2010

8. Burton T., Sharpe D., Jenkins N., Bossanyi E., Wind Energy Handbook, John Wiley \& Sons, LTD, West Sussex, 2001.

9. Lateş, M. T., Velicu, R., CFD analysis and theoretical modelling of multiblade small Savonius wind turbines. Proceedings of The $4^{\text {th }}$ International Conference on Sustainable Energy, 2014, Braşov, România.

10. Romanian Standard, no. 6055, Gear ratio (in romanian).

11. Săulescu, R., Jaliu, C., Climescu, O., Diaconescu, D. On the use of 2 DOF planetary gears as "speed increaser" in small hydros and wind turbines. Proceedings of the ASME 2011, IDETC/CIE 2011, Washington, DC, USA, CD Proceedings. 